\title{
Allelopathy Effects of Silver Nanoparticle Synthesis by Green Method from Pulicaria undulate
}

\author{
Eman R. Elsharkawy ${ }^{1,2^{*}}$ \\ ${ }^{1}$ Eco-physiology Unit, Department of Plant Ecology and Ranges, Desert Research Center, Cairo, \\ 15753, Egypt \\ ${ }^{2}$ Department of Chemistry, Faculty of Science, Northern Border University, KSA.
}

Author's contribution

The sole author designed, analyzed, interpreted and prepared the manuscript.

Article Information

DOI: 10.9734/ARRB/2019/v32i230078

Editor(s):

(1) Dr. Amit Kesarwani, Assistant Professor, Department of Agronomy, College of Agriculture, G. B. Pant University of Agriculture \& Technology, India.

(2) Dr. George Perry, Dean and Professor of Biology, University of Texas at San Antonio, USA.

Reviewers:

(1) E. Siva Rami Reddy, Tantia University, India. (2) Naumih M. Noah, United States International University Africa, Kenya. (3) Subhranshu Sekhar Samal, International Advanced Research Centre for Powder Metallurgy and New Materials, India. Complete Peer review History: http://www.sdiarticle3.com/review-history/47925

Original Research Article

Received 02 April 2019

Accepted 22 June 2019 Published 28 June 2019

\begin{abstract}
Nanotechnology nowadays has good potential application in many fields, especially in agriculture and industries. This study investigated the allelopathic effects of aqueous extract of Pulicaria undulate and nanoparticle synthesis by eco-friendly method from silver nitrate and water extract of Pulicaria undulate on seed germination of two weeds species. Aqueous extract and silver Nanoparticles plant extract (AgNPs) had an inhibitory effect on seed germination of common (Lepidium sativum, and Trifolium repens) as compared with control. Lpidum stavium seed germination was inhibited by nanoparticle and water plant extract at $100 \%$ concentration at the end of 10 day incubation period, at low concentration $25 \%$ of aqueous extract and AgNPs the germination ratio of $\mathrm{L}$. sativium reached $(30 \%$ and $5 \%)$ where for Trifolium repens the germination ratio were $(50 \%$ and $0 \%$ respectively). Nanoparticle are green synthesis by simple methods, using the aqueous extract of pulclaria leave and silver nitrate, the confirmation of nanoparticle was done by different methods UV-Vis spectroscopy (UV-Vis), Fourier transform infrared spectroscopy, (FTIR), transmission electron microscopy (TEM). The UV-visible spectra revealed the absorption peak at $449 \mathrm{~nm}$, while the emission peak of $\mathrm{Ag}$ was detected at $466 \mathrm{~nm}$. SEM analysis revealed that the synthesis of Ag NPs was spherical in shape and has an average size (13.3-23.8 nm). The
\end{abstract}

*Corresponding author: E-mail: elsharqawyeman2017@gmail.com, elsharqawyeman@hotmail.com; 
concentration of plant showed a dangerous role in size and dispersion of NPs, the decrease occurs at low concentration this confirms the plant are oxidizing in nature. Herein we suggest the use of nanoparticle synthesis from $\mathrm{Ag}$ nitrate and aqueous extract of Pulicaria undulate as herbicide instead of synthetic herbicide after further studies to confirm the results.

Keywords: Pulicaria undulate; herbicide; nanoparticles; TEM; allelopathy.

\section{INTRODUCTION}

In the last 20 years nanoparticles have been studied by many researchers, photonic properties of silver particles are interesting in biochemical and biomedical usage [1].

Nanoparticles play an important role in pharmaceutical, industrial, and biotechnological applications. Especially, silver nanoparticles have been studied and showed a potential antimicrobial, antiplasmodial and larvicidal activity $[2,3]$.

The synthesis of the nanoparticle by biological methods using plant extract is eco-friendly alternatives method. Using plants for nanoparticle synthesis can be advantageous over other biological processes because it eliminates the complicated process of maintaining cell cultures and can also be suitably scaled up for large-scale nanoparticle synthesis [4].

Nanotechnology has good potential for applications in agriculture, but there is still a long way down to reach the field. It is impossible to know all the details about how a nanotool will work in a particular crop, but we need to start with real field and in-plant tests. If we stay behind the limit of basic research only, the risk of agricultural nanotechnology becoming hype increases, hindering any further attempts for applications and research [5].

Pulcularia undulate is a traditional plant famous Southern Egypt and Saudi Arabia, people used to treat inflammation, and used as herbal tea. It is also used as an insect repellent $[6,7]$ studded the composition of oil of the fresh aerial parts of P. undulata (L.) kastel (from Saudi Arabia) by $\mathrm{GC} / \mathrm{MS}$. The oil is rich in phenolic compounds and monoterpene hydrocarbons and comparatively low in sesquiterpene hydrocarbons Arezou Ghahghaei 2014 [8], show that $P$. undulata extract has anti-aggregation properties, although in vivo the effectiveness of $P$. undulata extract remains to be investigated, it should be considered as a possible drug candidate or lead component of drugs to prevent or delay protein aggregation and amyloid disease [8].

The role of allelopathy or secondary metabolites in overcoming arid conditions, in conjunction with their allelopathic behaviour, is still poorly understood. On the other hand, our current understanding of allelopathy has been successfully used to control weed populations via methods involving crop rotation, mixed cropping and essential oils [9].

The aim of the present study green synthesis silver nanoparticle from desert growing plant Pulcularia undulate and study the allopathic effect of Ag NPs (silver nanoparticles) on the germination of some harm weeds.

\section{EXPERIMENTAL}

\subsection{Materials and Methods}

Healthy leaves of githgath, scientific name Pulicaria undulate were collected from ElQantara Sharq in North Sinai, Egypt, (Fig. 1). The plant was identified in the desert research centre and the authentic sample was kept in herbarium of DRC.

\subsection{Preparation of Plant Extract}

The Leaves of plant sample were dried in shade at room temperature for 3 days, then powdered using kitchen blender. Plant powder of dried clean sample $10 \mathrm{gm}$ was mixed in $500 \mathrm{ml}$ of distilled water and the mixture was boiled for 30 minutes then filtered by Whatman filter paper, the filtrate was kept under $4 \mathrm{C}^{\circ}$ for further use.

\subsection{Synthesis of Silver Nanoparticles}

For Synthesis silver nanoparticles, $1.5 \mathrm{ml}, 1 \mathrm{ml}$, $0.8 \mathrm{ml}, 0.6 \mathrm{ml}$ and $0.5 \mathrm{ml}$ and $0.2 \mathrm{ml}$ of plant extract was added to $5 \mathrm{ml}$ of $1 \mathrm{~m} \mathrm{M} \mathrm{AgNO}$ solution in $250 \mathrm{ml}$ flask and shaking for the bioreduction of $\mathrm{Ag}^{+}$to $\mathrm{Ag}^{\circ}$. The formation of nanoparticles was preliminarily confirmed by color change from faint yellow to dark brown. The Mixture was incubated in the dark at $37^{\circ} \mathrm{C}$ until used for analysis. 

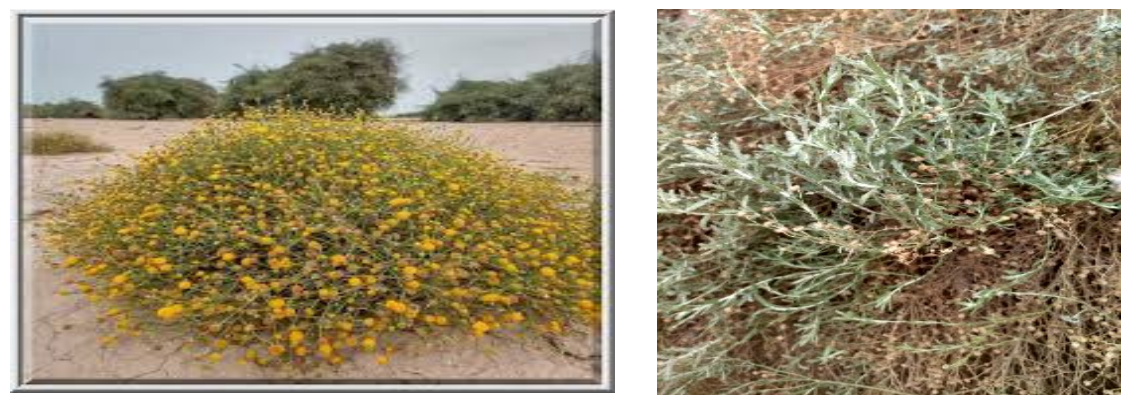

Fig. 1. Picture of plant

\subsection{Characterizations Nanoparticles}

The confirmation of Silver Nanoparticles synthesis was conducted at Advanced Materials and Nanoscale Research Laboratory, Ain Shams university by UV-visible spectra were recorded at room temperature using a Shimadzu 2600 spectrophotometer. UV-vis spectra of AgNPs and $\mathrm{Ag}$ ions were measured at 200 to $800 \mathrm{~nm}$ [10].

\subsection{Tem Analysis of Silver Nanoparticles Analysis}

The size and morphology of the nanoparticles were examined by TEM images were obtained on a JEOL-1200JEM for the TEM measurements.

\subsection{Allelopathic Study}

Germination tests were carried out in clean Petri dishes, according to the guidelines of the Association of Official Seed Analysis (AOAC, 1988).

The following parameters were measured:

Germination percentage (G\%): calculated as the number of germinated seeds/total number of seeds $\times 100$ according to ISTA, 1999).

The experiment was performed according to the methods described by Wu et al. [11], Lepidium sativum, and Trifolium repens seeds were germinated in Petri dishes 10 seeds were placed in each plate. The Petri dishes divided into two groups, one group was irrigated by $4 \mathrm{ml}$ from AgNPS extract and other group irrigated by $4 \mathrm{ml}$ plant aqueous extract, then incubated in the dark at $27 \mathrm{C}^{\circ}$ for $(48 \mathrm{~h})$, as control, the germinated seed was irrigated by distilled water. Each treatment was tested in three replicates. After incubation, the number of germinated seed was count and growth parameters were recorded.

\subsection{Statistical Analysis}

The data analyzed using analysis (ANOVA) test, the means of treatment were grouped on the basis of LSD at the 0.05 probability level.

\section{RESULTS}

Pulicaria undulate plant extract was used for the synthesis of AgNPS under unsophisticated conditions. It was observed that the mixed of 0.5 $\mathrm{ml}$ of a plant extract with $5 \mathrm{ml}$ of $\mathrm{mM} \mathrm{AgNO}$, the colour begin to change after 2 hours at room temperature $\left(27 \mathrm{C}^{\circ}\right)$ from yellow to brown which indicate the formation of AgNPs Fig. 2.

Under the similar condition, the change in the colour of other concentration occurs after 48 hours This colour change occurred also faster at $60 \mathrm{C}^{\circ}$ (in less than 30 minutes) than at room temperature. This observation agrees with data reported by (Mohan Kumar et al. 2012) [12], where the speed of formation nanoparticles have been found to be increased by increasing temperature and incubation period [12].

The formation of silver nanoparticles (AgNPs) was monitored by UV-VIS analysis where AgNPs show absorption at visible range $380-450 \mathrm{~nm}$, according to the shape and size of [13].

\subsection{UV-VIS -Spectroscopy}

UV-Vis absorption spectroscopy was considered as an important tool in confirmation and monitor the synthesis process and stability of NPs solution. The absorption spectrum of NPs metals is affected by many factors, including particle size, shape and particles-particles particleparticle interaction with the medium. thus, the 
aqueous bioreduction of $\mathrm{Ag}+$ ions can be efficiently monitored by UV-VIS. Fig. 3, demonstrate the absorption spectra of AgNPs synthesis at different concentration, The results reveal that the beast concentration for synthesis AgNPs is $0.5 \mathrm{ml}$ of plant extract with $5 \mathrm{ml} \mathrm{AgNO}$, synthesis of AgNPs from $P$. undulata is significantly faster at $0.5 \mathrm{ml}$ and after 2 hours this the beast condition, which is visibly reflected by regular increase in the intensity of the surface plasmon resonance (SPR) and after $120 \mathrm{~min}$ there is no further colour change this indication for the completion of reaction. As the concentration of the plant extract increases, the absorption peak gets more sharpness and the blue shift was observed from 458 to $446 \mathrm{~nm}$. The blue shifted and sharp narrow shape SPR band indicating the formation of a spherical and homogeneous distribution of silver nanoparticles was observed [13]. It should be mentioned that the extract absorption has a maximum at about $400 \mathrm{~nm}$ and could contribute to the absorption of AgNPs at high extract concentration.

\subsection{Fourier Transform Spectroscopy (Ftir)}

FTIR spectrum was used to identify the possible functional groups of biomolecules of plant extract, that might be responsible for bioreduction Fig. 4, illustrated the spectrum of IR of plant extract which showed a broadband at $3447 \mathrm{~cm}^{-1}$. This band attributed to the $\mathrm{OH}$ groups in the biomolecules. The IR bands at 2837 and 2852 $\mathrm{cm}^{-1}$ due to $\mathrm{C}-\mathrm{H}$ stretching vibration modes in hydrocarbon chains. The IR bands at 1326 and $1789 \mathrm{~cm}^{-1}$ were characterized as $\mathrm{C}-\mathrm{O}$ and $\mathrm{C}=\mathrm{O}$ stretching modes of the carbonyl functional group. The stronger band at $1686 \mathrm{~cm}^{-1}$ was characterized as $\mathrm{C}=\mathrm{O}$ of the amide groups of protein in the plant, Medium bands at $1072 \mathrm{~cm}^{-1}$ due to the $\mathrm{C}-\mathrm{O}-\mathrm{C}$ and $\mathrm{C}-\mathrm{OH}$ vibrations are observed. In the case of AgNPs, a large shift in the absorbance peak with decreased band intensity was observed from 3071.4 to 3447 $\mathrm{cm}^{-1}$ and 1382.2 to $1320 \mathrm{~cm}^{-1}$. The spectra also illustrate a prominent shift in the wave numbers corresponding to amide $\left(1652.5-1600 \mathrm{~cm}^{-1}\right.$ ), validates that free amino $\left(\mathrm{NH}_{2}\right)$ groups in compounds of the plant extract have interacted with AgNPs surface making AgNPs highly stable.

\subsection{Tem Analysis}

Transmission Electron Microscope (TEM) analysis method used for determined the shape and size of biosynthesis NPs, from the image of silver NP at Fig. 5 revealed that AgNPs have spherical shape and size range from (13.3-23.8 $\mathrm{nm})$ are) in which few nanoparticles are agglomerated. The TEM images confirm the formation of the nanoparticles and the size also comes in agree with UV data.

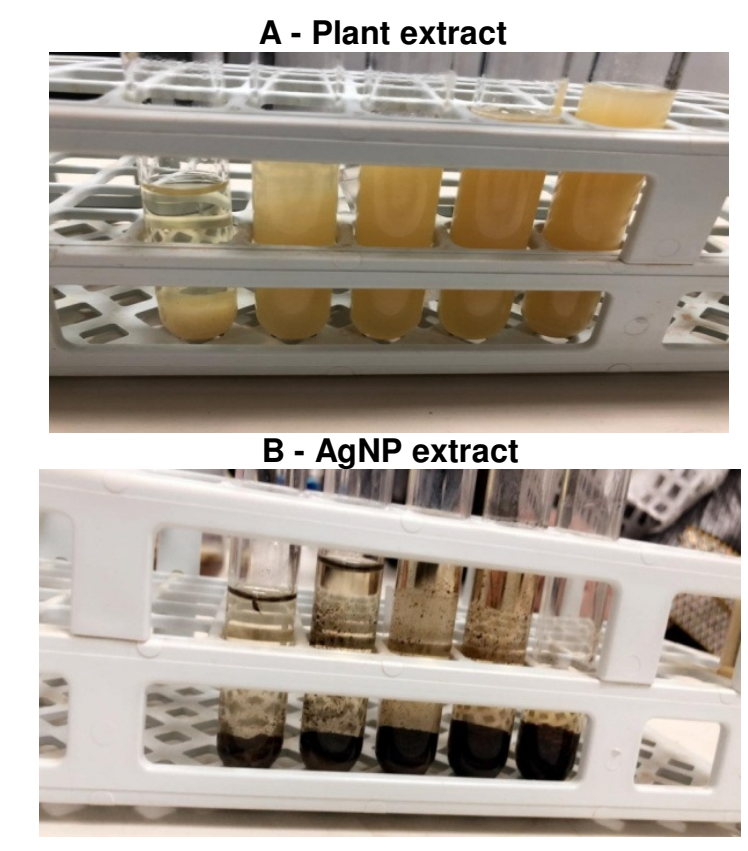

Fig. 2. Colore change of plant extract and AgNPs extract 


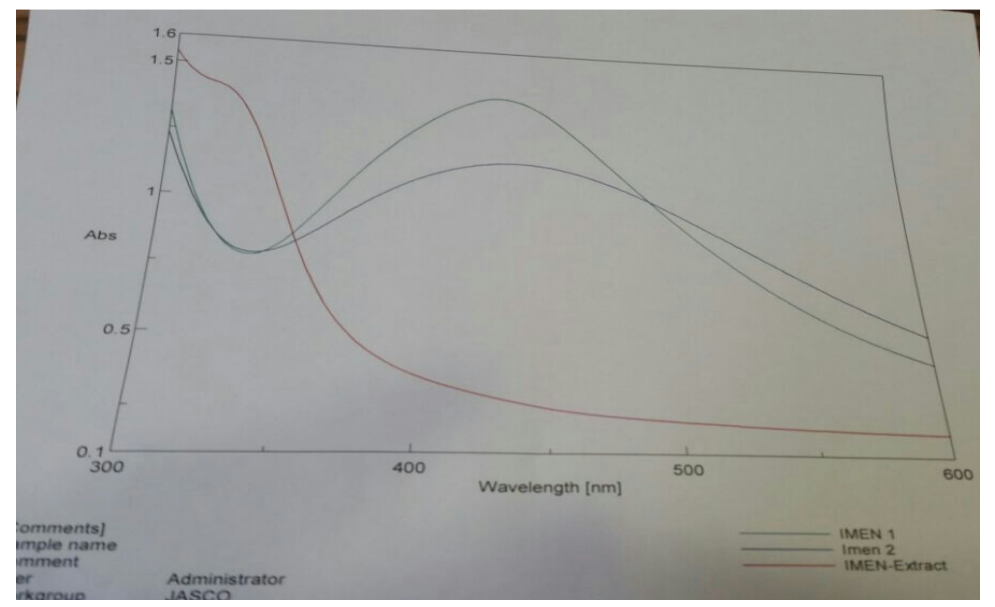

Fig. 3. UV-vis spectra of silver nanoparticles AgNPs using different concentrations of plant extract

\subsection{In-vitro Allelopathic Effect and Seed Germination}

The experiment was carried out to study the allelopathic effect of silver nanoparticle, and aqueous extract Pulicaria undulate on the germination of two weeds (Lepidium sativum, Trifolium repens). The effects of aqueous extract and nanoparticles on the germination and growth parameters of two harm weeds after 10 days in Petri dishes are shown in Tables 1 and 2.

Both aqueous extract and AgNps, have been shown inhibition of seed germination compared with control, the inhibition ratio was time dependent on the concentration, where the $100 \%$ of aqueous extract and AgNPs give $100 \%$ inhibition of seed germination of both weeds. Nanoparticle (AgNPs) showed strong inhibition of two weeds Lepidium sativum, Trifolium repens), furthermore at low concentration.

\subsection{Seedling Growth}

The effect of aqueous extract and AgNPS on root and shoot length of two species under study showed the same effect on germination, the reduction in shoot and root length come in parallel with the increasing concentration as illustrated in Table 2, The root length of Lepidum sativum and Trifolium repens, were significantly reduced by aqueous plant extract, which completely inhibited the root growth. In the application of low concentration, $25 \%$ of plant extract showed significantly increased root length, whereas the higher concentrations induced significant gradual reductions in root length. The effect of aqueous extract on shoot length show strongly reduction in the length of shoot, which gives indication the plant affect on the enzyme responsible on shoot elongation, the inhibition of shoot elongation of Lepidum sativum by plant extract is more strongly than Trifolium repens, the degree of inhibition of shoot and root increased gradually in parallel with increasing concentration of plant extract.

Table 1. Effect of plant extract and silver nanoparticle on the germination of Lepidum sativum and Trifolium repens

\begin{tabular}{lllll}
\hline $\begin{array}{l}\text { Conc } \% \\
\left(\mathbf{1 ~ g ~} / \mathbf{1 0 0} \mathbf{~ m l ~ H}_{\mathbf{2}} \mathbf{O}\right)\end{array}$ & \multicolumn{2}{c}{ Lepidum sativum } & \multicolumn{2}{c}{ Trifolium repens } \\
\hline & $\begin{array}{l}\text { Germination \% } \\
\text { plant extract }\end{array}$ & $\begin{array}{l}\text { Germination } \% \\
\text { nanoparticle }\end{array}$ & $\begin{array}{l}\text { Germination \% } \\
\text { water extract }\end{array}$ & $\begin{array}{l}\text { Germination \% } \\
\text { nanoparticle }\end{array}$ \\
\hline 100 & $0 \%$ & 0 & $0 \%$ & 0 \\
75 & $13 \%$ & 0 & $5 \%$ & 0 \\
50 & $18 \%$ & 0 & $25 \%$ & 0 \\
25 & $30 \%$ & 0 & $50 \%$ & 0 \\
\hline
\end{tabular}


A

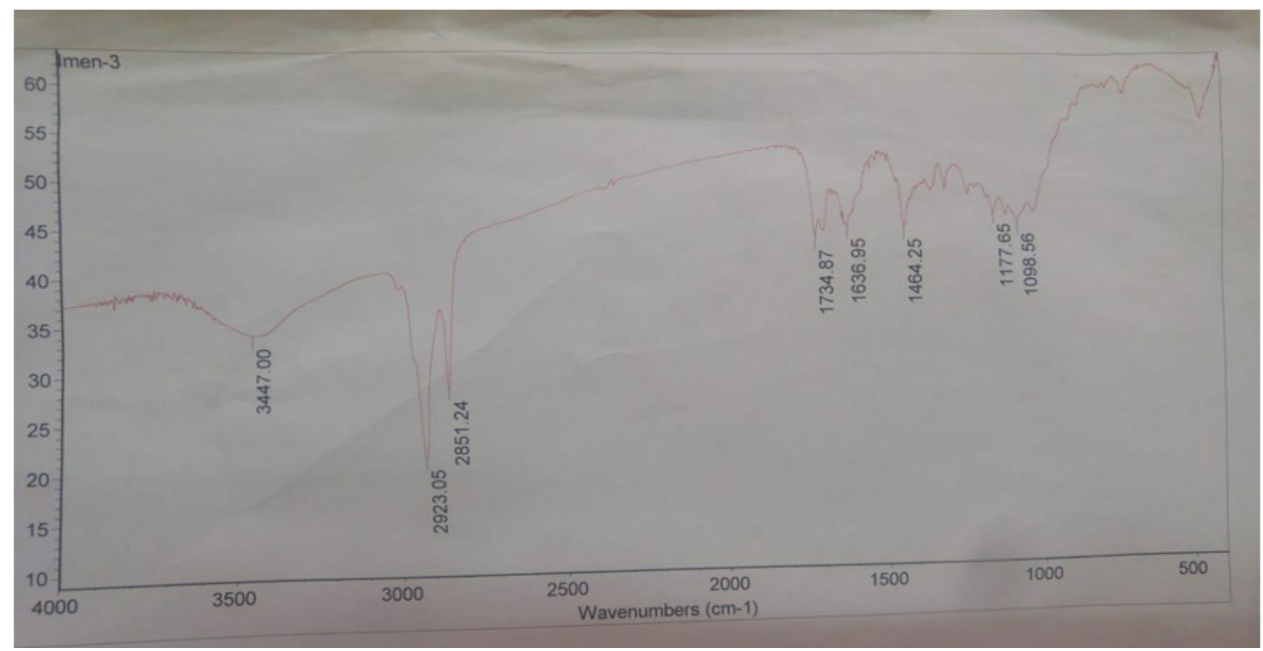

B

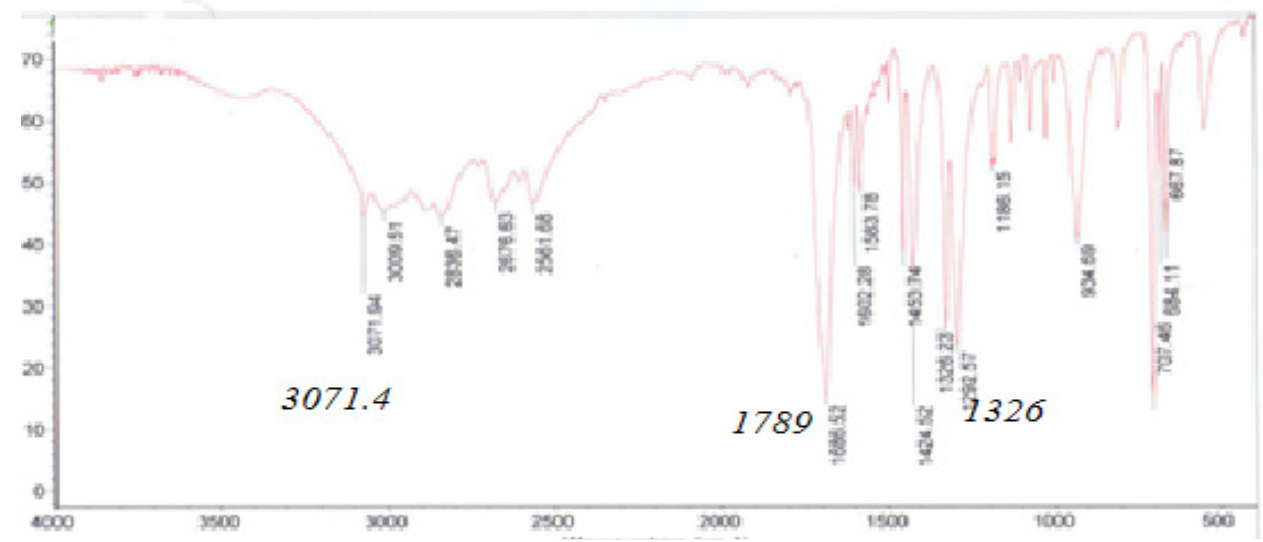

Fig. 4. IR spectra of (A) plant extract (B) silver nanoparticles

\section{DISCUSSION}

Nanoparticles have been considered as an important area of research due to their unique and tunable surface plasmon resonance (SPR) and their applications in biomedical science including tissue/tumour imaging, photothermal therapy and antimicrobial [2]. So in this study we aimed to add other application of silver nanoparticles in industrial and agriculture field we aimed to synthesis nanoparticle, prepared by green method from aqueous extract of Pulclaria undulate and silver nitrate, and use as herbicide by study the role of nanoparticle in the inhibition of germination of two weeds which grow in crops and affect the production of crop.

Allelopathy effect is phenomena can be used in inhibition of germination of weeds, some plant has allelopathic effect, inhibit the germination of some seed and stimulate the germination of other, as found by Sardans and Peñuelas [14], Teerarak et al. [15]. Hussain et al. reported that Allelopathy is a well-studied phenomenon in which chemicals released by one plant may have detrimental or inhibitory effects on the germination, Weeds interfere with crops by inhibiting their germination and seedling establishment [16].

Seed germination and seedling growth were more inhibited by AgNPs than aqueous extract, whereas, with an increase in concentration, there was a decrease in germination percentage and seedling growth. Germination of two weeds was affected slightly by the lower concentration of extracts, the shoot length, and root length also affected by the highest concentration. There is a clear reduction in shoot and root length of two weeds compared by control. 
Table 2. Effect of plant extract and silver nanoparticle on the growth parameters of weeds

\begin{tabular}{lllll}
\hline & Lepidum sativum & \multicolumn{3}{c}{ Trifolium repens } \\
\hline $\begin{array}{llll}\text { CONC } \% \\
\left(1 \mathrm{~g} / 100 \mathrm{ml} \mathrm{H}_{2} \mathrm{O}\right)\end{array}$ & $\begin{array}{l}\text { Germination water } \\
\text { extract } \%\end{array}$ & $\begin{array}{l}\text { Germination } \\
\text { Nanoparticle } \%\end{array}$ & $\begin{array}{l}\text { Germination } \% \text { water } \\
\text { extract }\end{array}$ & $\begin{array}{l}\text { Germination } \\
\text { Nanoparticle \% }\end{array}$ \\
\hline Shoot length & & & & \\
\hline $100 \%$ & 0 & 0 & 0 & 0 \\
$75 \%$ & 0 & 0 & $28 \%$ & 0 \\
$50 \%$ & $84 \%$ & 0 & $83 \%$ & 0 \\
$25 \%$ & $88 \%$ & 0 & $94 \%$ & 0 \\
& Water extract & Germination & Water extract & Germination \\
& $\%$ Germination $\%$ & Nanoparticle \% & Germination $\%$ & Nanoparticle \% \\
\hline Root length & & & & \\
\hline $100 \%$ & 0 & 0 & 0 & 0 \\
$75 \%$ & 0 & 0 & 0 & 0 \\
$50 \%$ & $68 \%$ & 0 & $76 \%$ & 0 \\
$25 \%$ & $84 \%$ & 0 & $88 \%$ & \\
\hline
\end{tabular}

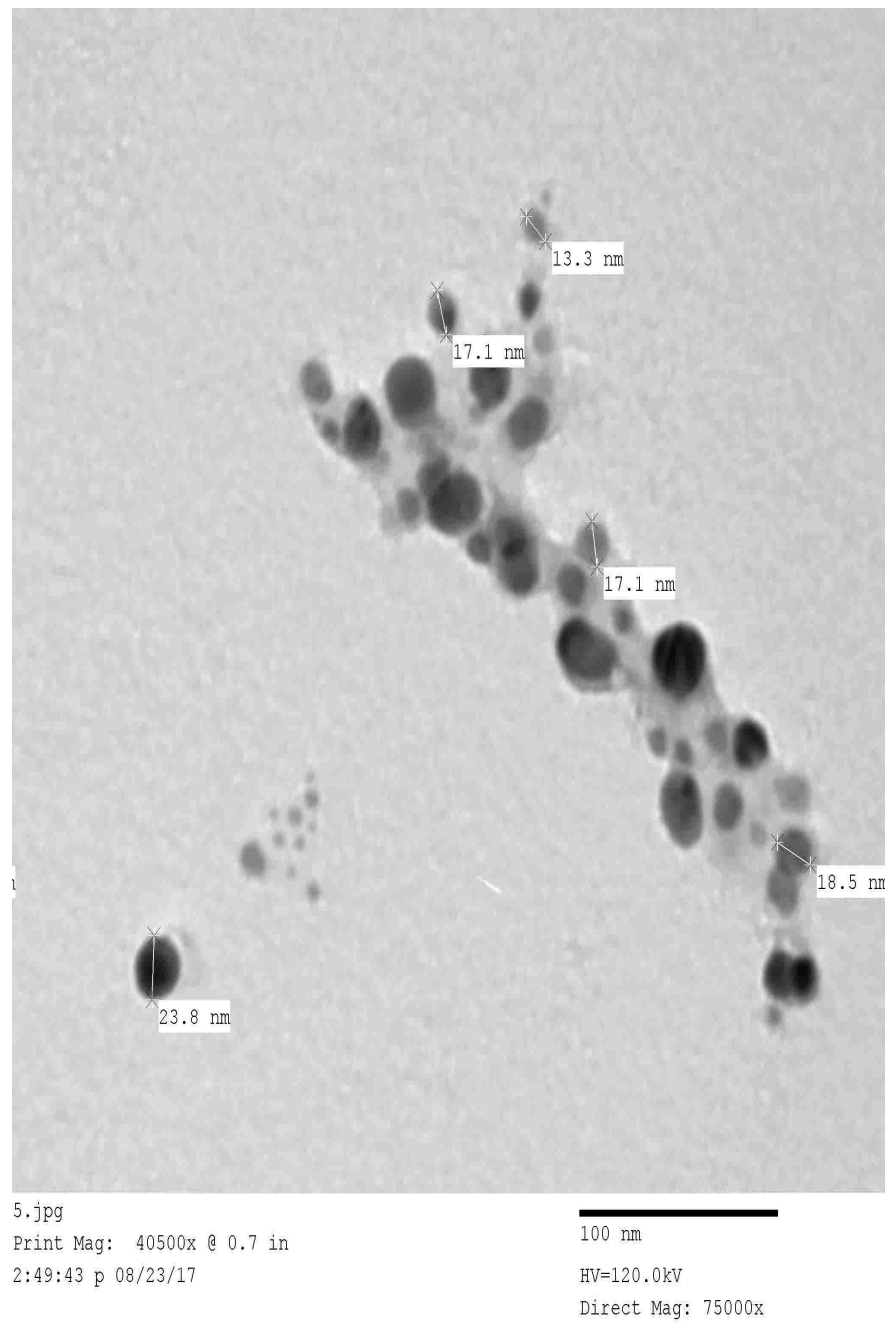

Fig. 5. TEM of AgNPs using plant Pulicaria undulate 
The study agrees with (Ashfaq et al., 2014) [17] who reported that the interaction between $C$. esculentus and $P$. hysterophorus showed a significant effect on germination rate, plumule length, radical length, fresh weight, and dry weight of seeds.

The formation of NPs was preliminary showed initial by colour change after the addition of aqueous plant extract to silver nitrate solution, the colour change from pale-yellow, then light brown to dark brown with reaction time due to excitation of surface plasma [18] the formation of NPs which confirmed also by (Uvvisible spectrophotometer and TEM).

\section{CONCLUSION}

The biosynthesis of Ag NPs using traditionally medicinal plant Bioreductive synthesis of $\mathrm{Ag}$ NPs using a medicinally Pulcularia undulate, yielded spherical nanoparticles with average size (13.3-23.8 nm) with average size $18.5 \mathrm{~nm}$. The inhibition of germination of $\mathrm{Ag}$ NPs and aqueous extract was studied on two weeds Lepidium sativum, Trifolium repens and revealed $100 \%$ seed germination inhibition for synthesis Ag NPs, and the inhibition goes in parallel with the concentration. The present study assessed the potential of nanoparticle for allelopathy on harm weeds. Many further studies recommended for identification of some bioactive compounds.

\section{COMPETING INTERESTS}

Author has declared that no competing interests exist.

\section{REFERENCES}

1. Krenn JR, Leitner A, Aussenegg FR. Metal nano-optics. In encyclopedia of nanoscience and nanotechnology Nalwa HS, Ed American Scientific publishers: Los Angeles, CA; 2003.

2. Saxena A, Tripathi RM, Singh RP: Biological synthesis of silver nanoparticles by using onion (Allium cepa) extract and their antibacterial activity. Dig J Nanomater Bios. 2010;5(2):427-432.

3. Krishnaraj C, Jagan EG, Rajasekar S, Selvakumar P, Kalaichelvan PT: Synthesis of silver nanoparticles using Acalypha indica leaf extracts and its antibacterial activity against water borne pathogens. Colloids Surf B Biointer. 2010;76:50-56.
4. Sankar R, Rizwana K. Ultra-rapid photocatalytic activity of Azadirachta indica engineered colloidal titanium dioxide nanoparticles. App nanosci; 2014.

5. Pérez-de-Luque A. Interaction of nanomaterials with plants: What do we need for real applications in agriculture? Front. Environ. Sci. 2017;5:12.

DOI: 10.3389/fenvs.2017.00012

6. Elshiekh YH, Abd El, Moniem MA: Gas chromatographyemass spectrometry analysis of Pulicaria crispa (whole plant) petroleum ether extracts. Am $\mathrm{J}$ Res Commun. 2005;3:58e67.

7. Mossa JS, Hifnawy MS, AI-Yahya MA, AlMeshal IA, Mekkawi AG: GC/MS analysis of essential oils of Pulicaria arabica and $P$. undulata. Pharm Biol. 1987;25:113-119.

8. Ghahghaei A, Valizadeh J, Nazari S, Ravandeh M: Chaperone potential of Pulicaria undulata extract in preventing aggregation of stressed proteins, AAPS Pharm Sci Tech. 2014;15(3).

9. Schulz M, Marocco A, Tabaglio V, Macias FA, Molinillo JMG: Benzoxazinoids in rye allelopathy-from discovery to application in sustainable weed control and organic farming. J Chemical Ecol. 2013;39:154174.

10. Masoud EA, Al-Hajry M, Al-Marrani. A antibacterial activity of silver nanoparticles synthesized by Sidr (Ziziphus spinaChristi) leaf extract against pathogenic bacteria. Int. J. Curr. Microbiol. App. Sci. 2016;5(4): 226-236.

11. Wu H, Pratley J, Lemerle D, Haig T, An M. Screening methods for the evaluation of crop allelopathic potential. Botanical Review. 2001;64:403-415.

12. Mohan Kumar K, Sinha M, Mandal BK, Ghosh AR, Siva Kumar K, Sreedhara Reddy P. Green synthesis of silver nanoparticles using Terminalia chebula extract at room temperature and their antimicrobial studies. Spectrochim Acta A Mol Biomol Spectrosc. 2012;91:228233.

13. Sathishkumar G, Gobinath C, Karpagam K, Hemamalini V, Premkumar K, Sivaramakrishnan S: Phyto-synthesis of silver nanoscale particles using Morinda citrifolia L. and its inhibitory activity against human pathogens. Colloids Surf B Biointerfaces. 2012;95:235-240.

14. Sardans J, Peñuelas J. The role of plants in the effects of global change on nutrient availability and stoichiometry in the plant- 
soil system. Plant Physiol. 2012;160: 1741-1761.

15. Teerarak M, Laosinwattana C, Charoenying $\mathrm{P}$, Kato-Noguchi $\mathrm{H}$. Allelopathic activities of Jasminum officinale f. var. grandiflorum (Linn.) Kob.: Inhibition effects on germination, seed imbibition, and a-amylase activity induction of Echinochloa crus-galli (L.) Beauv. African J Biotechnol. 2012; 11:7850-7854.

16. Hussain $M$, Farooq $M$, Shahzad M, Basra A, Lee DJ. Application of Moringa allelopathy in crop sciences. Allelopathy. 2013;469-483.

17. Ashfaq M, Ali1 A, Haider MS. Allelopathic association between weeds extract and rice (Oryza sativa L.) seedlings. Journal Of Pure \& Applied Microbiology. (Spl. Edn. 2). 2014;8:573580.

18. Khalil MMH. Green synthesis of silver nanoparticles using olive leaf extract and its antibacterial activity. Arab $\mathrm{J}$ Chem. 2014;7:1131-1139.

(c) 2019 Elsharkawy; This is an Open Access article distributed under the terms of the Creative Commons Attribution License (http://creativecommons.org/licenses/by/4.0), which permits unrestricted use, distribution, and reproduction in any medium, provided the original work is properly cited.

Peer-review history:

The peer review history for this paper can be accessed here: http://www.sdiarticle3.com/review-history/47925 